\title{
Meiosis and Maternal Aging: Insights from Aneuploid Oocytes and Trisomy Births
}

\author{
Mary Herbert ${ }^{1,2}$, Dimitrios Kalleas², Daniel Cooney ${ }^{2}$, Mahdi Lamb ${ }^{2}$, and Lisa Lister ${ }^{2}$ \\ ${ }^{1}$ Newcastle Fertility Centre, Centre for Life, Times Square, Newcastle upon Tyne NE1 4EP, United Kingdom \\ ${ }^{2}$ Wellcome Trust Centre for Mitochondrial Research, Institute of Genetic Medicine, Newcastle University, \\ Newcastle upon Tyne NE1 3BZ, United Kingdom \\ Correspondence: mary.herbert@ncl.ac.uk
}

In most organisms, genome haploidization requires reciprocal DNA exchanges (crossovers) between replicated parental homologs to form bivalent chromosomes. These are resolved to their four constituent chromatids during two meiotic divisions. In female mammals, bivalents are formed during fetal life and remain intact until shortly before ovulation. Extending this period beyond $\sim 35$ years greatly increases the risk of aneuploidy in human oocytes, resulting in a dramatic increase in infertility, miscarriage, and birth defects, most notably trisomy 21. Bivalent chromosomes are stabilized by cohesion between sister chromatids, which is mediated by the cohesin complex. In mouse oocytes, cohesin becomes depleted from chromosomes during female aging. Consistent with this, premature loss of centromeric cohesion is a major source of aneuploidy in oocytes from older women. Here, we propose a mechanistic framework to reconcile data from genetic studies on human trisomy and oocytes with recent advances in our understanding of the molecular mechanisms of chromosome segregation during meiosis in model organisms.

$\mathrm{H}$ uman female fertility declines markedly during the fourth decade of life, resulting in an extended postreproductive lifespan. According to our current understanding, female reproductive lifespan is curtailed by two forces. First, the stock of germ cells (oocytes) present in the ovary at birth (approximately one million) becomes depleted throughout life. This culminates in the menopause when the population of oocytes dwindles to $\sim 1000$ and the hormonal triggers controlling the reproductive cycle cease to function, resulting in cessation of ovulation (te Velde et al. 1998; Broekmans et al. 2007; Adhikari and Liu 2009). Meno- pause typically occurs around the age of 50 $\mathrm{yr}$ and is remarkably consistent among diverse populations (Lambalk et al. 2009; Kirkwood and Shanley 2010). However, menopause is preceded by a sharp increase in the incidence of infertility, miscarriage, and birth defects (notably Down's syndrome, trisomy 21) from the mid-30s onward (Hassold and Hunt 2001; Nagaoka et al. 2012). This has major implications for human reproductive health, especially in developed economies in which there is an increasing trend for women to delay childbearing until after the age of 35 (Schmidt et al. 2012).

Editors: Stephen Kowalczykowski, Neil Hunter, and Wolf-Dietrich Heyer

Additional Perspectives on DNA Recombination available at www.cshperspectives.org

Copyright (C) 2015 Cold Spring Harbor Laboratory Press; all rights reserved; doi: 10.1101/cshperspect.a017970

Cite this article as Cold Spring Harb Perspect Biol 2015;7:a017970 
M. Herbert et al.

The formation of a diploid embryo requires that sperm and egg contribute exactly one copy of each chromosome. This necessitates a specialized cell division known as meiosis, in which haploid gametes are generated from diploid precursors. The vast majority of meiotic errors detected in human pregnancies result from errors in female meiosis, whereas $<5 \%$ are a result of errors in male meiosis (Hassold and Hunt 2001). Although all autosomal chromosomes are susceptible to missegregation during female meiosis (Handyside 2012; Fragouli et al. 2013), most errors are not compatible with development of embryos beyond the earliest stages. These manifest clinically as failed implantation, resulting in infertility. Some segregation errors, notably those resulting in trisomy $13,15,16,18$, or 21 , can develop to later stages. Data from these cases indicate that all except trisomy 16 (the most common chromosomal cause of miscarriage) occur at very low frequency $(<5 \%)$ up until the age of $\sim 35 \mathrm{yr}$ and then increase to varying extents thereafter (Nagaoka et al. 2012). Such pregnancies either abort spontaneously or, in rare cases, develop to term giving rise to birth defects, such as Down's syndrome (trisomy 21), Patau's syndrome (trisomy 13), or Edward's syndrome (trisomy 18). Of these, trisomy 21 is the most common, and the incidence of trisomy 21 pregnancy has increased dramatically in recent decades (Morris and Alberman 2009; Loane et al. 2013).

The association between female age and the incidence of Down's syndrome was first documented in the 1930s (Penrose 1933), yet the improbability of pregnancy in older women was already acknowledged in biblical times. Infertility is now estimated to affect $15 \%$ of all couples, and female age is considered to be the major etiological factor (Sharma et al. 2013). Despite the sustained increase in human lifespan, there is no convincing evidence of an upward trend in the age at which female reproductive function declines (Ellison 2010). Because of the widespread use of contraception and the many social and economic factors influencing human fertility rates, it is difficult to establish the precise correlation between female age and infertility in the general population. Data ob- tained from the Hutterite community, who are opposed to the use of birth control, indicate that female fertility declines progressively from the age of 20, and more sharply from the mid- to late 30s (Eaton and Mayer 1953; Nonaka et al. 1994). To address the possible confounding factor of reduced frequency of sexual intercourse with advancing age, a later study investigated the probability of pregnancy in women aged 19$39 \mathrm{yr}$ in which the timing of intercourse was known (Dunson et al. 2002). Although all age groups had a fertile window of $6 \mathrm{~d}$ around the time of ovulation, the probability of pregnancy was twice as high for women aged 19-26 yrcompared with those aged 35-39 yr (Dunson et al. 2002). Data obtained from women undergoing in vitro fertilization (IVF) treatment also show a marked age-related decline in the chance of pregnancy (Templeton et al. 1996; Sauer 1998).

Two lines of evidence from clinical infertility treatments provide definitive proof that the oocyte lies at the heart of the female reproductive aging problem. First, the age-related decline in female fertility is rescued by using oocytes donated by younger women (Sauer 1998). Second, evidence from clinical programs, in which euploid oocytes were selected for use in treatment on the basis of genome-wide analysis, indicates that oocytes from older women have an equivalent implantation potential to those obtained from younger women (Geraedts et al. 2011). Thus, defective chromosome segregation during meiosis is sufficient to explain the decline in reproductive function in premenopausal women. A key challenge, therefore, is to understand what goes wrong during the meiotic divisions of oocytes ovulated toward the end of the reproductive lifespan.

\section{MEIOSIS IN THE CONTEXT OF MAMMALIAN OOGENESIS}

The inheritance of exactly one copy of each chromosome during gametogenesis requires two rounds of chromosome segregation following a single round of DNA replication. This contrasts with mitotic cell division, in which daughter cells inherit two copies of each chromosome by undergoing alternate rounds of 
DNA replication and chromosome segregation. The first round of meiotic segregation (meiosis I $[\mathrm{MI}])$ is a reductional division involving disjunction of homologous chromosomes. This is followed by equational segregation of sister chromatids during meiosis II (MII).

The reductional division requires the establishment of physical linkages between paternal and maternal homologs to form a unique bivalent (or tetrad) chromosome structure. In most organisms, this is accomplished by reciprocal exchange of DNA between homologous chromosomes to generate crossovers (Neale and Keeney 2006; Baudat et al. 2013). Maintenance of the bivalent chromosome structure requires that chiasmata (the cytological manifestation of crossovers) are stabilized by arm cohesion distal to the sites of crossover formation (Moore and Orr-Weaver 1998; Petronczki et al. 2003). Dissolution of arm cohesion during anaphase I converts bivalents to dyad chromosomes consisting of two sisters linked by cohesion between centromeres. Accurate segregation during MI depends on sister centromeres adopting a unified, side-by-side configuration, which promotes binding of their kinetochores to microtubules emanating from the same spindle pole (Hauf and Watanabe 2004). The resulting monopolar kinetochore-microtubule attachments are unique to MI and are essential for the reductional division. In contrast, sister centromeres biorient during MII and establish bipolar kinetochore-microtubule attachments (Hauf and Watanabe 2004). On dissolution of centromeric cohesion during anaphase II, sisters segregate to opposite poles (Fig. 1A).

Although the mechanics of meiosis are broadly conserved between all sexually reproducing organisms, meiosis in female mammals is characterized by a number of distinctive features. Strikingly, although regulated by genetically separable pathways (Dokshin et al. 2013), female meiosis is coordinated with the protracted process of oogenesis. Commencing during fetal life, it is not completed until after the mature oocyte is fertilized. Thus, in stark contrast to sperm, whose journey from diploid precursor to haploid gamete commences just weeks before fertilization, decades can elapse between the formation and resolution of bivalent chromosomes in oocytes. In addition, whereas male meiosis results in the production of four sperm atazoa, a single oocyte is the sole viable product of female meiosis. Half of the chromosomes from each of the two meiotic divisions are ejected in nonviable structures known as the first and second polar bodies (Fig. 1B). This enables the oocyte to retain the cytoplasmic resources to support subsequent embryonic development.

Female meiosis is preceded by multiple rounds of mitotic division, giving rise to several million oogonia, which enter into meiotic prophase I and undergo meiotic recombination, following a round of premeiotic DNA replication. The resulting oocytes arrest in meiotic prophase I, with their bivalent chromosomes contained in a large nucleus, known as the germinal vesicle $(\mathrm{GV})$, surrounded by a small amount of cytoplasm. A layer of flattened pregranulosa cells surrounds the oocyte to form the primordial follicle. Primordial follicles are recruited for growth throughout life. However, growing follicles cannot develop to the preovulatory stage until after puberty. In sexually mature females, follicle-stimulating hormone (FSH) promotes granulosa cell proliferation and production of estradiol, which triggers a preovulatory surge of luteinizing hormone (LH) (Fig. 1C) (McGee and Hsueh 2000; Edson et al. 2009). The LH surge induces breakdown of the intercellular junctions between the oocyte and its surrounding granulosa cells, causing a decline in oocyte levels of cAMP and activation of the M-phase kinase Cdk1 (Mehlmann 2005; Jaffe and Norris 2010; Von Stetina and OrrWeaver 2011). This drives the transition from prophase arrest to $\mathrm{M}$ phase of $\mathrm{MI}$, which is marked by breakdown of the GV membrane and assembly of the MI spindle. The MI spindle then migrates to the oocyte cortex by an actindependent mechanism to facilitate polar body formation (Azoury et al. 2008; Schuh and Ellenberg 2008).

Anaphase I occurs at the oocyte cortex following dissolution of arm cohesion by the protease separase. Bivalents are converted to dyads, and those that segregate to the outermost spindle pole are lost to the first polar body, whereas 
M. Herbert et al.

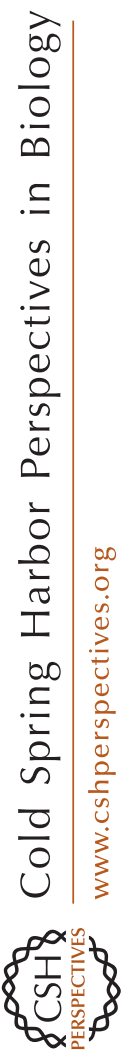

A

$\mathbf{A}$
$\overline{0}$
$\mathbb{8}$
$\overline{0}$
은

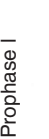

B

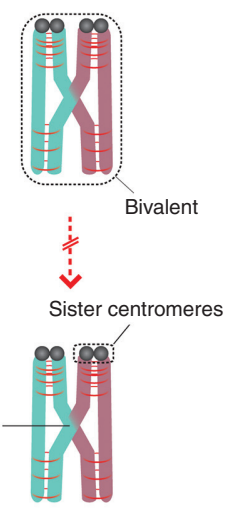

Bivalent biorientation
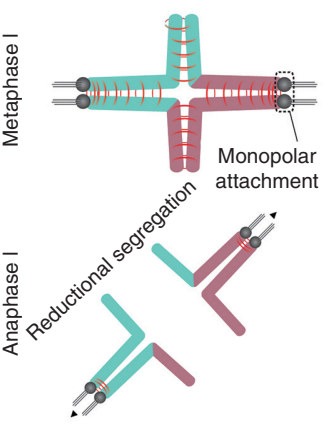

Dyad mono-orientation
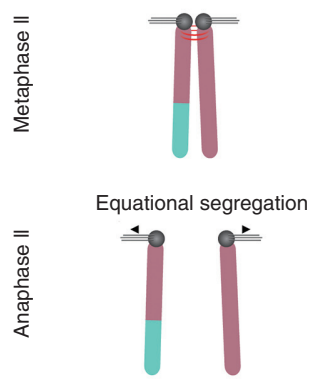

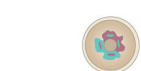

Prophase I arrest (primordial oocyte)$$
\text { (primo }
$$$$
\text { . }
$$

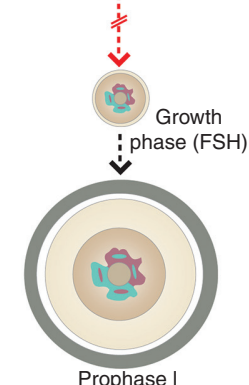

Prophase I
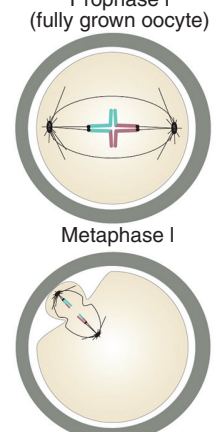

PB1

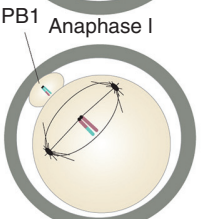

Metaphase II arrest
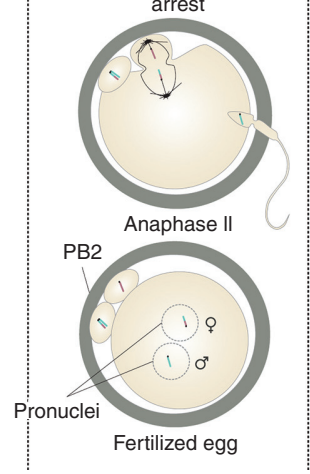

Anap

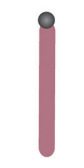

C

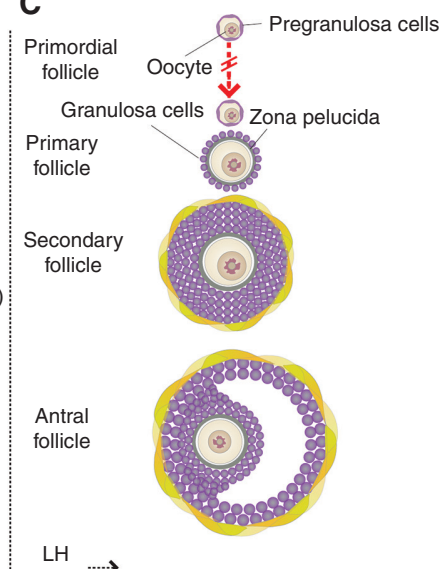

surge $\cdots$
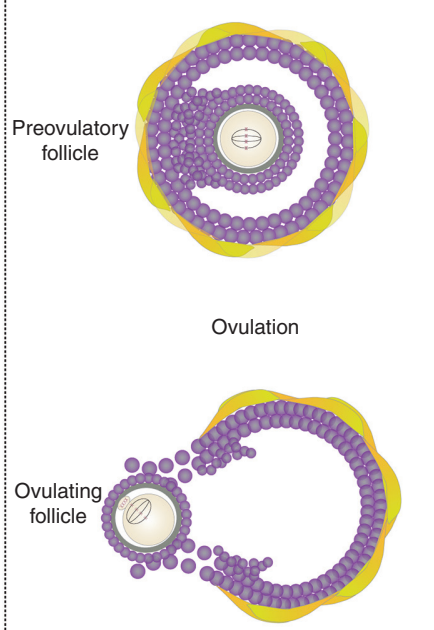

Figure 1. Meiotic divisions and mammalian oogenesis. (A) Bivalent chromosome consisting of replicated maternal and paternal homologs linked by a crossover (chiasma). Accurate segregation of homologs during meiosis I (MI) depends on biorientation of bivalents, which necessitates monopolar attachment of sister kinetochores. Dissolution of cohesion from chromosome arms during anaphase I (anaI) converts bivalents to dyads. Dissolution of centromeric cohesion results in segregation of chromatids during anaphase II. $(B, C)$ Following the formation of bivalent chromosomes, oocytes arrest in prophase of MI surrounded by a layer of pregranulosa cells to form primordial follicles. Primordial follicles are recruited for growth on an ongoing basis. (Legend continues on following page.) 
Human Aneuploidy, Infertility, and Maternal Age

those remaining in the oocyte biorient their sister centromeres and align on the MII spindle. The oocyte is ovulated at this stage $(\sim 36-38 \mathrm{~h}$ after the LH surge in humans) and remains arrested in MII by an activity known as cytostatic factor (CSF). The fertilizing sperm induces a calcium-signaling cascade, which inactivates CSF, triggering completion of MII (Schmidt et al. 2006; Swann and Lai 2012). Dissolution of centromeric cohesion during anaphase II is followed by segregation of sister chromatids (at least one of which has recombined with its nonsister homolog). Half of these are lost to the second polar body. The oocyte's haploid maternal and paternal genomes are then separately packaged in the male and female pronuclei of the fertilized egg ( 1 cell zygote), in which they undergo DNA replication in preparation for the first zygotic division.

According to our current understanding, oocytes ovulated throughout reproductive life are derived from the pool of primordial follicles established during fetal life. This is dramatically reduced before birth and is, then, further depleted throughout life. It is estimated that of the approximately seven million oocytes formed during fetal life, one million remain at birth, reducing to $\sim 400,000-600,000$ by the time of puberty and to $\sim 1000$ by menopause (te Velde et al. 1998; Broekmans et al. 2007; Adhikari and Liu 2009). The vast majority of ovarian follicles are lost by apoptotic cell death known as follicular atresia (McGee and Hsueh 2000), and depletion of the oocyte pool during reproductive life is generally referred to as ovarian aging. Ovarian aging occurs in parallel with the increased incidence of meiotic segregation errors.

In summary, bivalent chromosomes established by homologous recombination during meiotic prophase are resolved to their four constituent chromatids by stepwise loss of cohe- sion during two successive meiotic divisions. In female mammals, bivalents are formed in utero, but are not resolved to dyads until shortly before ovulation. Dyads are not resolved to chromatids until anaphase II is triggered by the fertilizing sperm. Oocytes ovulated late in reproductive life are derived from a depleted ovarian pool and differ from their earlier counterparts in the duration of prophase I arrest. The genetic evidence from oocytes and cases of trisomy (Nagaoka et al. 2012) indicate that extending this period beyond $35 \mathrm{yr}$ results in a dramatically increased incidence of segregation errors during the meiotic divisions.

\section{MOLECULAR MECHANISMS OF MEIOSIS AND ANEUPLOIDY: CHROMOSOME STRUCTURE}

The establishment of physical linkages between maternal and paternal homologs through reciprocal exchange of DNA is essential for genome haploidization during mammalian gametogenesis. Meiotic recombination occurs during meiotic prophase I, which is classically divided into distinct stages defined by chromosome cytology (Fig. 2A). Recombination is initiated at DNA double-strand breaks (DSBs) and it culminates in the formation of double Holliday junctions (dHJs), which, in humans, are resolved to form crossovers. DSBs are created by the nuclease Spo11 (Keeney and Neale 2006), which is targeted to a subset of $>25,000$ recombination hotpots, by the sequence-specific DNA-binding capacity of the histone methyltransferase, PRDM9. Recombination between sex chromosomes is confined to a small region of homology, called the pseudoautosomal region and, at least in mouse, appears to be PRDM9 independent (Baudat et al. 2013). Recombination between homologs, rather than sisters, is promot-

Figure 1. (Continued) Growing follicles do not develop to the preovulatory stage until after puberty when they become responsive to follicle-stimulating hormone (FSH). Fully grown oocytes enter M phase following a surge of luteinizing hormone (LH). During anaphase I, the outermost dyads are ejected in the first polar body (PB1). The dyads remaining in the oocyte realign on the meiosis II (MII) spindle. The oocyte is then ovulated and remains arrested at metaphase of MII until sperm entry triggers anaphase II when half of the chromatids are ejected in the second polar body (PB2). Fertilization is marked by formation of pronuclei, in which the maternal and paternal haploid genomes are separately packaged. 
M. Herbert et al.

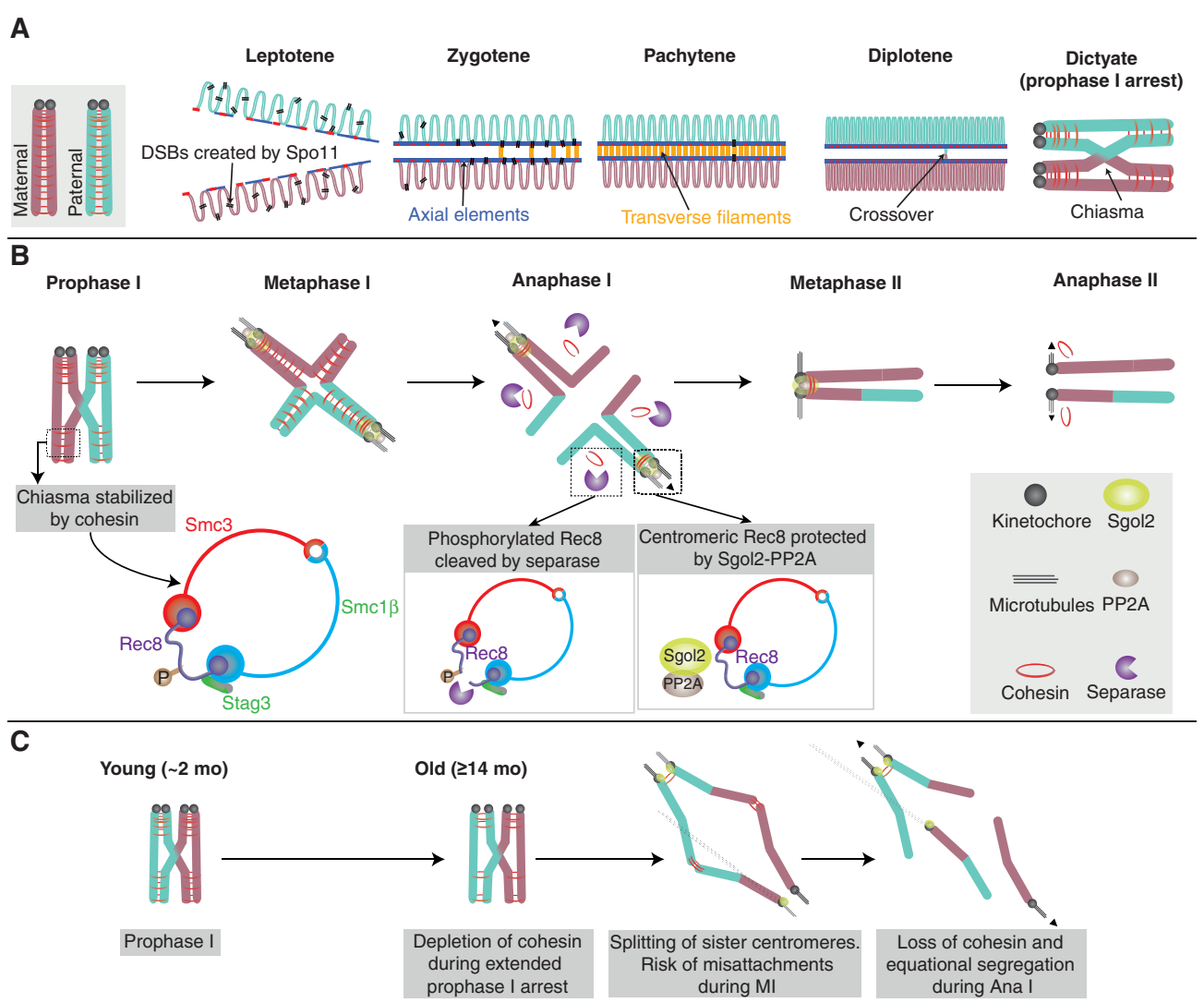

Figure 2. Molecular regulation of meiotic chromosome structure. (A) Replicated maternal and paternal homologs undergo meiotic recombination following entry into prophase I. The process is initiated by Spo11-mediated double-strand break (DSB) formation. Axial elements support DSB formation and DNA repair from the homolog. The synaptonemal complex (SC) promotes formation of double Holliday junctions ( $\mathrm{dHJ}$ ), which are resolved to crossovers. Crossovers become visible as chiasmata in diplotene and oocytes then enter dictyate (prophase I arrest). (B) Bivalent chromosomes are stabilized by arm cohesin distal to the chiasma. The cohesin ring shown contains meiosis-specific subunits: the $\alpha$-kleisin Rec8, Smc1 $\beta$, forms a heterodimer with Smc3 and Stag3, which regulates stability of Rec8-containing complexes. During anaphase I, separase cleaves phosphorylated Rec 8 on the chromosome arms. Cohesin at the centromere is protected by the phosphatase PP2A, which is recruited there by Sgo12. Dyad chromosomes align on the meiosis II (MII) spindle and cohesin at the centromere is cleaved during anaphase II. (C) Schematic summarizing the main elements of the "cohesin deterioration hypothesis," based on findings in mouse oocytes. Cohesin loaded in early oogenesis becomes depleted during prolonged arrest in prophase I. This results in loss of bivalent structure, which, in mice, manifests as distally associated homologs. Sister centromeres also lose their unified structure and frequently undergo premature resolution followed by equational (shown) or reductional segregation.

ed by rod-like, proteinaceous structures called axial elements, which run along the length of chromosomes and consist of cohesin, condensin, and meiosis-specific proteins. In late prophase ( pachytene), the axial elements of homologs become linked in a zipper-like manner by transverse filaments to form the synaptonemal complex (SC) in which recombination interme- diates are processed to form $\mathrm{dHJ}$ (Page and Hawley 2004).

DSB repair between homologs results in two outcomes: crossovers and noncrossovers. In humans and mice, noncrossovers outnumber crossovers by an order of magnitude (Baudat et al. 2013). Although crossover formation involves reciprocal exchange of large chromosome 
intervals that link homologs, noncrossovers result in very local nonreciprocal gene conversion and do not connect homologs. Specification of crossovers involves stabilization of recombination proteins on selected DSB sites (Reynolds et al. 2013; Qiao et al. 2014). Progression through prophase I is regulated by the recombination checkpoint, which monitors DSB repair and chromosome synapsis by an ATR-dependent mechanism (Hochwagen and Amon 2006) involving Hormad proteins in mammals (Daniel et al. 2011). Crossover sites are transiently marked by the DNA mismatch repair complex Mlh1-Mlh3, and, following SC disassembly, crossovers become visible as chiasmata (Svetlanov and Cohen 2004). Oocytes then enter a state of arrest in meiotic prophase I, also known as dictyate (Fig. 2A).

Accurate segregation during $\mathrm{MI}$ requires at least one crossover per pair of homologs. The distribution of crossovers is determined in part by PRDM9, a rapidly evolving protein, of which 40 allelic variants have been identified in humans (Baudat et al. 2013). In general, oocytes form more crossovers than sperm. Nevertheless, the regulation of crossing over is thought to be less rigorous in oocytes, and achiasmate homologs, which fail to form the obligatory crossover required for efficient disjunction, have been observed in 10\% of oocytes (Nagaoka et al. 2012). These segregate as two univalent chromosomes during anaphase I and account for a significant fraction of aneuploidy in humans. Evidence from cases of human trisomy indicates that single chiasmate bivalents are also prone to missegregation depending on the site of crossover formation (Lamb et al. 1996). However, population studies indicate that the relationship between the chiasmate configurations and risk of trisomy changes during female aging (Robinson et al. 1998; Lamb et al. 2005; Oliver et al. 2008; Ghosh et al. 2009), suggesting an interaction with defects acquired subsequent to crossover formation.

As a consequence of crossover formation during meiotic recombination, cohesion between sister chromatids is essential for the stability of bivalent chromosomes. In mitosis and meiosis, sister chromatid cohesion is mediated by the evolutionarily conserved cohesin complex (Nasmyth and Haering 2009). This complex forms a large tripartite ring consisting of a V-shaped heterodimer of Smc1 and Smc3, which is closed by an $\alpha$-kleisin subunit. The cohesin ring topologically entraps replicated DNA molecules and holds sister chromatids together until the onset of anaphase (Nasmyth and Haering 2009; Nasmyth 2011; Peters and Nishiyama 2012). The $\alpha$-kleisin subunit recruits Pds5 and Scc3 (SA1/SA2), which regulate release and stabilization of cohesin. Only the cohesin complexes loaded during DNA replication confer cohesion capable of withstanding the splitting forces exerted by bipolar kinetochore-microtubule attachments (Nasmyth 2011; Peters and Nishiyama 2012). In accordance with this, evidence from mouse oocytes indicates that the cohesin complexes loaded early in oogenesis are sufficient to maintain bivalent stability until cohesin is removed from chromosome arms during anaphase I (Revenkova et al. 2010; Tachibana-Konwalski et al. 2010).

A number of meiosis-specific cohesin subunits have been identified (Fig. 2B). These include the conserved $\alpha$-kleisin subunit Rec8, which is a paralog of the mitotic $\alpha$-kleisin Rad21/Scc1. Mammalian meiocytes also contain Smc1 $\beta$, a meiosis-specific ortholog of the mitotic Smc1 (Smc1 $\alpha$ ), and a paralog of SA1/2, known as STAG3 (McNicoll et al. 2013). An additional meiosis-specific $\alpha$-kleisin subunit, called $\operatorname{Rad} 21 \mathrm{~L}$, has recently been identified in mammals and is present primarily during early prophase (Gutierrez-Caballero et al. 2011; Ishiguro et al. 2011; Lee and Hirano 2011). Meiosisspecific cohesin subunits, together with mitotic subunits, form up to six different cohesin complexes in mammalian meiosis (Lee and Hirano 2011; McNicoll et al. 2013). However, only Rec8containing complexes confer cohesion in mouse oocytes (Tachibana-Konwalski et al. 2010).

The properties and functions of $\operatorname{Rec} 8$ are ideally tailored to support genome haploidization. First, Rec8 is important for a normal level and distribution of DSBs, and facilitates recombination between homologs rather than sisters (Kugou et al. 2009; Kim et al. 2010). Second, Rec8 enables centromeric cohesion to be pro- 
M. Herbert et al.

tected from separase during anaphase I. Unlike Scc1, cleavage of Rec 8 by separase depends on its phosphorylation, which, in budding and fission yeast, is mediated by Casein kinase $1 \delta$ and Cdc7-Dbf4 (Ishiguro et al. 2010; Katis et al. 2010). Centromeric Rec8 is dephosphorylated by PP2A and is, consequently, protected from separase during anaphase I. Protection of centromeric cohesion is essential for bipolar attachment and accurate segregation of sisters during anaphase II. PP2A is recruited to centromeres by orthologs of the Drosophila Mei-S332 protein, known as Shugoshin (Sgo) proteins (Gutierrez-Caballero et al. 2012; Watanabe 2012). In mouse oocytes, protection of centromeric cohesion is mediated by Sgol2 (Shugoshin-like protein 2), one of two members of the Sgo family expressed in mammals (Fig. 2B) (Lee et al. 2008; Llano et al. 2008).

Monopolar attachment of sister kinetochores on the MI spindle is essential for biorientation of bivalents and, hence, accurate segregation of homologs. In budding yeast, monopolar attachment is mediated by the monopolin complex (Toth et al. 2000) and, in fission yeast, by Moal and Rec 8 at the core centromere (Watanabe 2012). Recently, a meiosis-specific kinetochore protein (Meiken) has been reported to facilitate monopolar attachment in mouse oocytes (Kim et al. 2014). Monopolar attachment in fission yeast is also promoted by chiasmata (Hirose et al. 2011; Sakuno et al. 2011). Consistent with this, sister kinetochores of univalent chromosomes frequently establish microtubule attachments with both poles of the MI spindle in mouse oocytes (Le Maire-Adkins et al. 1997; Kouznetsova et al. 2007; Nagaoka et al. 2011) and yeast (Sakuno et al. 2011). Indeed, recent findings indicate that cleavage of Rec8 specifically at centromeres promotes biorientation of univalent chromosomes in mouse oocytes (Tachibana-Konwalski et al. 2013). This suggests that, as in fission yeast, centromeric Rec8 is important for mono-orientation of sister kinetochores in mammalian oocytes.

Insight into the importance of cohesin in stabilizing bivalent chromosomes during the protracted period of prophase arrest in mammalian oocytes came from the $\operatorname{Smcl} \beta^{-/-}$ mouse. It was found that $\operatorname{Smcl} \beta^{-/-}$oocytes, fixed during prometaphase I, show premature resolution of chiasmata and separation of sister centromeres. Crucially, the prevalence and severity of these defects increased during an extended period of prophase arrest (Hodges et al. 2005). Subsequently, studies in wild-type mice indicated that Rec8-containing cohesin complexes become depleted from oocyte chromosomes during female aging (Liu and Keefe 2008; Chiang et al. 2010; Lister et al. 2010). Oocytes with reduced chromosomal cohesin showed an increased incidence of homologous pairs without visible chiasmata, which, instead, remained associated at the telomeres (Fig. 2C). This was accompanied by a reduction in the proportion of single-chiasmate bivalents (Lister et al. 2010), suggesting that single chiasmate bivalents are particularly susceptible to destabilization during female aging.

Although destabilization of chiasmata is likely to be an effect of depletion of Rec8-containing complexes from chromosome arms, Rec8 at centromeres was also dramatically reduced. This was associated with an increased distance between sister centromeres, such that the majority of sister pairs appeared as two wellseparated foci (Chiang et al. 2010; Lister et al. 2010). In addition, recruitment of the centromeric cohesin protector Sgol2 was reduced in wild-type oocytes from aged females and in Smcl $\beta^{-/-}$oocytes from young females (Lister et al. 2010). These data suggest that depletion of centromeric Rec8 is associated with disruption of the unified structure of sister centromeres and reduced recruitment of its own protector. Consistent with the latter, prematurely separated sisters are prevalent in MII-arrested oocytes from aged females (Chiang et al. 2010; Lister et al. 2010; Yun et al. 2014).

Cohesin complexes identified in the mouse also mediate chromosome cohesion in human oocytes. It was initially reported that chromosome-associated cohesin in human oocytes showed no marked reduction in the age range 18-34 yr (Garcia-Cruz et al. 2010a). More recently, however, immunofluorescence labeling of human ovarian sections indicated a significant reduction in the levels of Rec 8 and Smc1 $\beta$ 
during female aging (Tsutsumi et al. 2014). Although significant, the magnitude of the effect was quite modest, possibly caused by the presence of soluble cohesin (not associated with chromosome axes), which, in mouse oocytes, does not appear to decline during female aging (Chiang et al. 2010). Further support for a cohesin defect in human oocytes comes from the growing body of evidence indicating that premature resolution of centromeric cohesion is a major route to aneuploidy in oocytes of older women (Pellestor et al. 2006; Handyside 2012).

In conclusion, the age-related deterioration of bivalent structure in $S m c 1 \beta^{-/-}$oocytes, together with depletion of chromosomal cohesin in wild-type oocytes, gave ground to the "cohesin deterioration hypothesis." According to this idea, depletion of cohesin below a certain threshold results in destabilization of chiasmata and separation of sister centromeres, which, in turn, compromises monopolar attachment during MI and bipolar attachment during MII (Fig. 2C). Although this hypothesis provides a plausible molecular link between female aging and missegregation during the meiotic divisions, the primary causes and mechanisms underlying cohesin depletion remain to be elucidated. As mentioned above, overall Rec8 level does not decline during female aging (Chiang et al. 2010), which implies that depletion of oocyte chromosomal cohesin is a problem of cohesin retention rather than replenishment. Whether this is a consequence of incomplete inhibition of separase, accumulation of damage to cohesion subunits, or age-related changes in chromatin structure remains to be established.

\section{MECHANISMS OF MEIOSIS AND ANEUPLOIDY: CHROMOSOME SEGREGATION}

As discussed above, accurate segregation of bivalents requires that they establish stable bipolar attachments on the MI spindle, which depends on mono-orientation of sister kinetochores (Fig. 2B). In mouse oocytes, bivalent-spindle attachments undergo multiple rounds of error
Human Aneuploidy, Infertility, and Maternal Age

correction before anaphase onset (Kitajima et al. 2011). This is inhibited by an Aurora B/ C kinase inhibitor (Kitajima et al. 2011). Consistent with this, Aurora B promotes monopolar attachment in budding (Monje-Casas et al. 2007) and fission yeast (Hauf et al. 2007), and is required to correct aberrant attachments during MI (Sakuno et al. 2011).

In addition to its role as a protector of centromeric cohesin, Sgol2 serves multiple functions at the kinetochore, including interactions with Aurora B and its kinase targets (GutierrezCaballero et al. 2012). Consistent with this, recent evidence indicates that Sgol2 promotes biorientation of bivalents in mouse oocyte. Oocytes lacking Sgol2 fail to form end-on kinetochore-microtubule attachments. Instead, they show lateral attachments (Rattani et al. 2013), which are typically observed during early prometaphase (Kitajima et al. 2011). A recent report indicates that lateral attachments are also prevalent in mouse oocytes from older females (Shomper et al. 2014). Taken together, these findings raise the possibility that, in addition to increasing the risk of cohesin cleavage at centromeres, defects in Sgol2 localization (Lister et al. 2010) may impede correction of aberrant kinetochore-microtubule attachments before the onset of anaphase I in oocytes from older females.

In mouse oocytes (Kudo et al. 2006), as in other meiotic systems (Petronczki et al. 2003), cleavage of Rec 8 by the protease separase converts bivalents to dyads during anaphase I. In mitotic cells, the onset of anaphase is coordinated with the establishment of stable bipolar attachments by the spindle assembly checkpoint (SAC). In the presence of unattached kinetochores, active SAC components inhibit anaphase-promoting complex (APC/C)-mediated proteolysis of the separase inhibitors securin and cyclin B (Musacchio and Salmon 2007; Lara-Gonzalez et al. 2012). Degradation of cyclin B and securin is also required for anaphase onset in mouse oocytes (Herbert et al. 2003; Touati et al. 2012) and, as in mitosis, the SAC regulates the timing of this (Homer et al. 2005; Niault et al. 2007; McGuinness et al. 2009). In addition, mouse oocytes arrest in MI 
M. Herbert et al.

when exposed to the microtubule-depolymerizing drug nocodazole, which generates unattached kinetochores (Wassmann et al. 2003).

Although mammalian oocytes appear to be equipped with a functional SAC, its ability to detect aberrant kinetochore-microtubule attachments during MI appears to be limited. For example, univalent chromosomes, which are a major source of aneuploidy in human oocytes, would be expected to activate the SAC because of the absence of tension. Consistent with this, oocytes of some mouse strains arrest in MI when a majority of chromosomes exist as univalents (Woods et al. 1999). Moreover, in fission yeast (Sakuno et al. 2011), anaphase onset is delayed in the presence of univalent chromosomes, and this delay is proportionate to the number of univalents present. However, univalents eventually satisfy the SAC through biorientation of sister centromeres in yeast (Sakuno et al. 2011) and mouse oocytes (Le Maire-Adkins et al. 1997; Kouznetsova et al. 2007; Nagaoka et al. 2011).

Consistent with the idea that the oocyte SAC may not be very sensitive, oocytes from women of all ages show aneuploidy as a result of loss or gain of dyads during anaphase I (Pellestor et al. 2006). This presumably arises because of the failure to detect univalent chromosomes or failure of bivalents to biorient correctly before anaphase I. Although it has been proposed that defects in SAC function might explain the agerelated increase in oocyte aneuploidy, oocytes from aged mice do not show accelerated onset of anaphase and they arrest in MI in response to nocodazole (Duncan et al. 2009; Lister et al. 2010; Sebestova et al. 2012). Furthermore, premature separation of sister centromeres, which cannot be detected by the SAC, is the major source of aneuploidy in oocytes from older women (see below) (Fig. 3B) (Pellestor et al. 2003).

In conclusion, although current evidence suggests that the SAC in mammalian oocytes may not be very sensitive, it does not support a major role for the SAC in the maternal age effect. However, it is possible that aging is associated with deterioration of the mechanisms responsible for activating the SAC through destabiliza- tion of erroneous kinetochore-microtubule attachments. This may be linked to structural changes at the kinetochores arising from cohesin depletion and reduced recruitment of Sgol2.

\section{TOWARD A MECHANISTIC FRAMEWORK FOR UNDERSTANDING THE MATERNAL AGE EFFECT}

Our current understanding of the pathways leading to female meiotic errors is based on genetic studies on trisomy cases and chromosomal analyses of oocytes from clinical IVF programs. As mentioned above, the trisomy data provide information on the risk of missegregation associated with the position and number of crossovers formed during fetal development. Because of its prevalence and compatibility with life, trisomy 21 had been the focus of population studies to unravel the relationship between maternal age and risks associated with specific chiasmate configurations (Oliver et al. 2008; Ghosh et al. 2009). In contrast to the trisomy data, which are based on clinically recognized pregnancies, oocyte analyses provide information on meiotic missegregation, irrespective of the potential for implantation. However, exogenous gonadotropins, which are used to stimulate growth of multiple ovarian follicles, may induce chromosome missegregation (Roberts et al. 2005; Baart et al. 2007). Despite this, all large-scale studies indicate that the incidence of oocyte aneuploidy increases from the age of $\sim 35 \mathrm{yr}$, and dramatically from the age of $\sim 38$ yr. In addition to the increase in the overall proportion of aneuploid oocytes, women $>38 \mathrm{yr}$ show a 10 -fold increase in aneuploidy involving multiple chromosomes (Pellestor et al. 2006; Handyside et al. 2012; Fragouli et al. 2013).

Although early studies were based on cytogenetic analysis of oocytes obtained from women undergoing IVF treatment, more recent studies involve whole genome amplification combined with array-based comparative genome hybridization (CGH), or sequencing. Remarkably, despite the technical challenges, analysis of polar body DNA by array CGH shows high concordance $(>90 \%)$ with the female pro- 
A

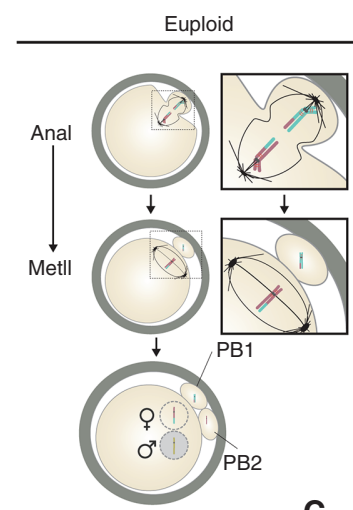

B

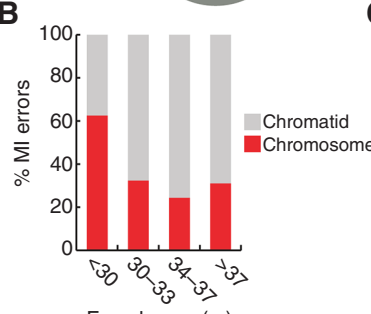

E Female age (yr)

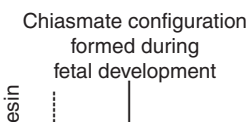
Achi

C
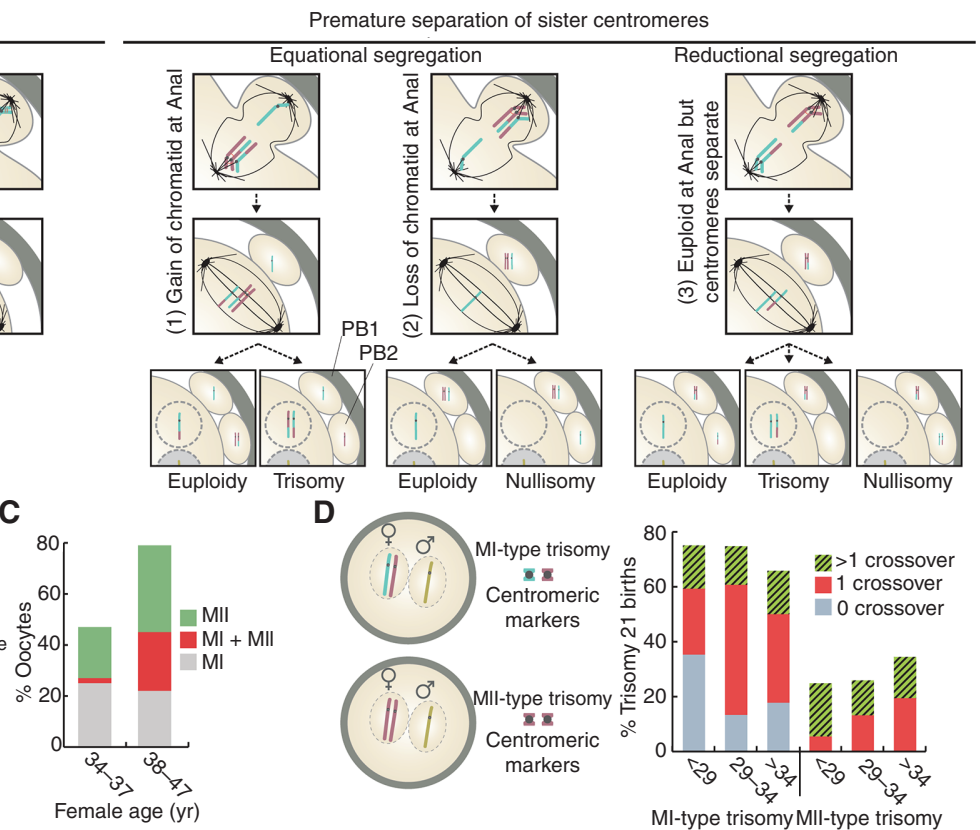

D

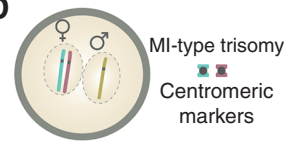

${ }^{80}$ [
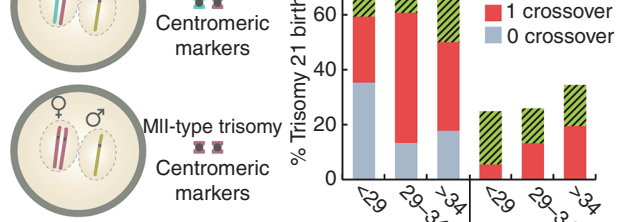
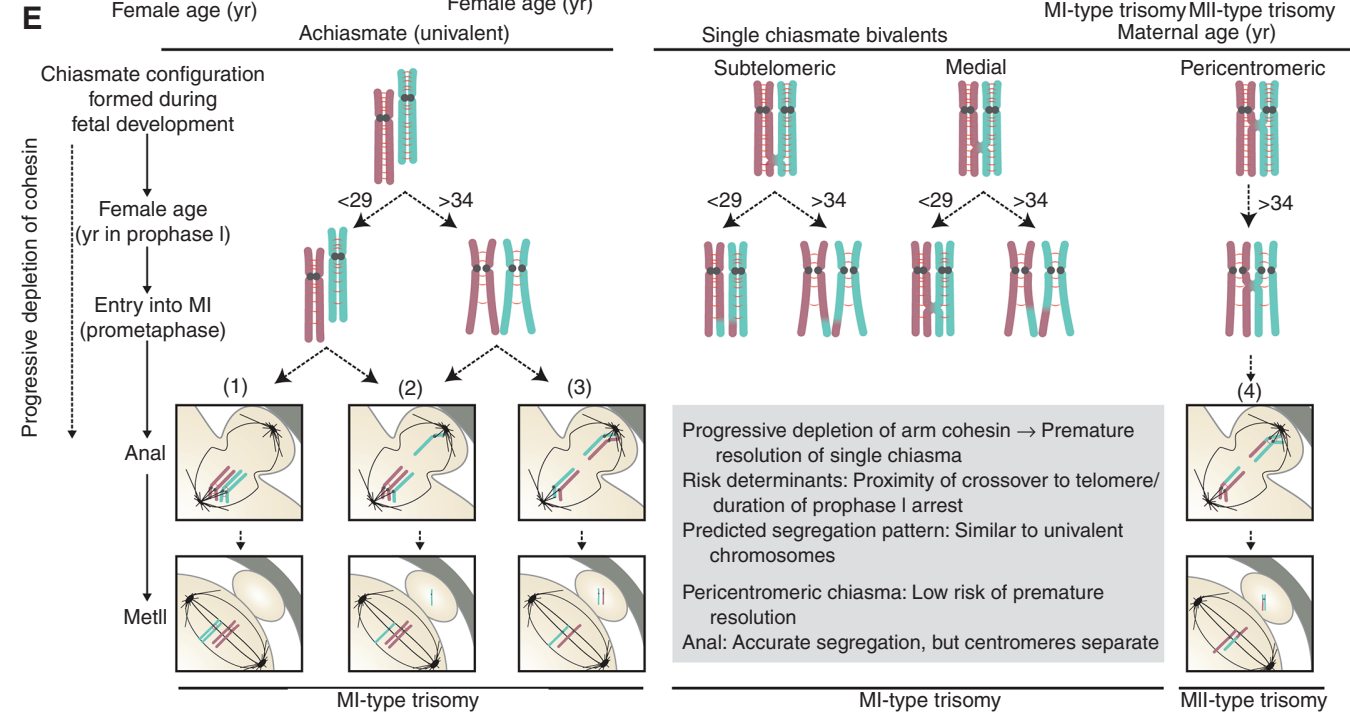

Figure 3. Chromosome structure and missegregation in human oocytes and maternal trisomy. $(A)$ Schematic showing the types of aneuploidy involving premature separation of sister centromeres described in human oocytes. (B) Graph showing the proportions of whole chromosome and chromatid errors reported from cytogenetic analysis of meiosis II (MII)-arrested human oocytes $(n=1397)$ from women of different ages. (Calculated from data in Pellestor et al. 2003.) (C) Graph showing the incidence of segregation errors occurring during each of the meiotic divisions in oocytes from younger and older women thought to be at high risk of meiotic aneuploidy. Based on array-comparative genome hybridization (CGH) analysis of both polar bodies from human oocytes/zygotes $(n=420)$ (Fragouli et al. 2013). (D) Schematic showing meiosis I (MI)- and meiosis II (MII)-type trisomy based on pericentromeric markers in the two maternally inherited copies. Graph shows the number of crossovers observed in MI- and MII-type trisomy 21 children across three maternal age groups (Oliver et al. 2008). (E) Model showing the predicted effect of a progressive depletion of arm cohesion on the structure of univalents and single chiasmate bivalents. Depletion of arm cohesion distal to the chiasma is predicted to induce its premature resolution. (Legend continues on following page.) 
M. Herbert et al.

nucleus (Geraedts et al. 2011; Handyside 2013). However, because these techniques are generally used to identify euploid zygotes for women known to be at high risk of meiotic errors, the incidence of aneuploidy is increased compared with the earlier cytogenetic studies. Reassuringly, although all chromosomes are susceptible to missegregation, the combined data from a number of studies indicate that the highest frequency of missegregation is observed for chromosomes 15, 16, 21, and 22 (Fragouli et al. 2011, 2013; Handyside et al. 2012), all of which have been identified in trisomic pregnancies (Risch et al. 1986).

A growing body of evidence indicates that aneuploidy in human oocytes is predominantly caused by premature separation of sister centromeres, resulting in loss of the dyad structure required for accurate segregation during MII (Fig. 3B). This was first reported by Roslyn Angell (1991) and was subsequently found to be strongly correlated with female age (Pellestor et al. 2003, 2006). Cytogenetic analysis of large series of MII-arrested oocytes indicated that the majority of aneuploid oocytes from younger women $(<30 \mathrm{yr})$ had errors involving whole chromosomes (dyads). However, missegregation of chromatids was the predominant cause of aneuploidy in oocytes of older women (Fig. 3B) (Pellestor et al. 2003). The prevalence of separated sisters has also been confirmed in molecular genetic studies (Gabriel et al. 2011; Handyside et al. 2012; Fragouli et al. 2013), ruling out the possibility that single chromatids were an artifact of chromosome-spreading techniques. The majority of MI errors from older women involve loss or gain of a single chromatid (Pellestor et al. 2006; Handyside 2012), indicating that separated sisters segregate equationally during MI (Fig. 3A1,A2). Howev- er, the presence of a pair of separated sisters in MII-arrested oocytes has also been reported in humans (Angell 1997; Sandalinas et al. 2002) and mice (Chiang et al. 2010). These findings indicate that premature resolution of centromeric cohesion is not always accompanied by equational segregation. Although reductional segregation accompanied by centromere separation does not cause aneuploidy in the MIIarrested oocyte, the presence of two free chromatids is a potent precursor of missegregation during anaphase II (Fig. 3A).

Given the prevalence of premature sister centromere separation, it is not surprising that oocytes of older women show an increased incidence of segregation errors during anaphase II (Fig. 3C) (Kuliev et al. 2011; Handyside et al. 2012; Fragouli et al. 2013). Although stochastic segregation of prematurely separated chromatids can result in the restoration of euploidy during anaphase II, the presence of multiple free chromatids in MII-arrested oocytes of older women greatly reduces the likelihood of this (Handyside et al. 2012; Fragouli et al. 2013). Moreover, widespread loss of centromeric cohesion may cause spindle instability, which has been reported in MII-arrested oocytes from older women (Battaglia et al. 1996; Volarcik et al. 1998; Coticchio et al. 2013). This would contribute to missegregation of intact dyads, as well as prematurely separated sisters. Spindle instability could also arise as a result of difficulty in biorienting sisters whose centromeres are not completely separated, but are distant from each other, as reported in MII oocytes from older mice (Chiang et al. 2010; Yun et al. 2014) and women (Duncan et al. 2012).

In conclusion, the evidence from chromosomal analyses indicates that oocytes from older women violate two cardinal rules of meiosis:

Figure 3. (Continued) The threshold level of cohesin required to maintain bivalent stability depends on the distance between the chiasma and the telomere. Bivalents with pericentromeric chiasma are, therefore, predicted to be more stable than those with a more distally posited chiasma. The predicted segregation patterns during MI are based on (1) evidence that premature separation of sister centromeres is the major cause of aneuploidy in human oocytes, (2) data from genetic analyses of trisomy 21 showing the incidence of MI- and MII-type errors associated with each of the chiasmate configurations stratified by maternal age (Oliver et al. 2008), and (3) findings in yeast meiosis (Sakuno et al. 2011) and mouse oocytes (Kouznetsova et al. 2007) that sister kinetochores of univalent chromosomes establish bipolar attachments on the MI spindle. 
(1) they fail to reliably protect centromeric cohesion until the onset of anaphase II, and (2) they do not reliably establish monopolar kinetochore-microtubule attachments during MI. This is consistent with findings in mouse oocytes (Chiang et al. 2010; Lister et al. 2010) and indicates that cohesin at centromeres, and the mechanisms responsible for its protection, become compromised during female aging. However, it remains to be established whether human oocytes show an age-related decline in levels of cohesin and its protectors Sgol2/PP2A, specifically at centromeres.

Although the defect in centromeric cohesion in oocytes of older women is likely to be a major cause of missegregation during both meiotic divisions, data from studies on human trisomy indicate that the risk of missegregation is also influenced by the chiasmate configurations created during fetal life. In these studies, the position and number of crossovers is inferred from the two maternally inherited copies (Lamb et al. 1997). Furthermore, the origin of the two maternally inherited copies can be inferred from analysis of pericentromeric markers. Heterozygosity implies that homologs failed to segregate reductionally, and these are referred to as MItype trisomy. Homozygosity, on the other hand, is indicative of failure to accurately segregate sisters during anaphase II, and these are referred to as MII-type trisomy (Fig. 3D). Importantly, the categorization of trisomy cases into MI- and MII-type errors does not necessarily correspond to the meiotic division in which the rules of meiosis were violated or, indeed, to the division in which a copy number error would be detected by chromosomal analysis of oocytes or polar bodies (for example, see Fig. 3E).

Chiasmate configurations inferred from cases of trisomy 21 include no crossover (achiasmate), 1 crossover (single chiasmate), and more than 1 crossover (Fig. 3D) (Lamb et al. 1997). The proportion of achiasmate cases is highest for young mothers $(<29 \mathrm{yr})$; this declines sharply for mothers aged $29-34 \mathrm{yr}$, but increases again thereafter (Lamb et al. 2005; Oliver et al. 2008; Ghosh et al. 2009). The nonlinear decline prompted the suggestion of an interaction with a defect acquired during maternal aging (Oliver
Human Aneuploidy, Infertility, and Maternal Age

et al. 2008). The proportion of single chiasmate bivalents increases with maternal age (Fig. 3D), and this is accompanied by a dramatic shift in the risk associated with the site at which the single crossover is formed. The vast majority of single chiasmate cases born to younger women show a crossover in the subtelomeric region (most distal 6.5 Mb) (Lamb et al. 2005). As women get older, the proportion of trisomic children with medially positioned crossovers increases (Lamb et al. 2005; Oliver et al. 2008; Ghosh et al. 2009). Furthermore, single pericentromeric crossover, positioned in the most proximal 3.5 Mb (Lamb et al. 2005), emerge as a risk factor for trisomy 21 as women get older (Fig. 3D) (Oliver et al. 2008; Ghosh et al. 2009). Thus, the data indicate that absence of crossovers and a single crossover positioned close to the telomere are the most susceptible to missegregation in oocytes of younger women. Although achiasmate homologs persist as a significant risk in older women, bivalents with more medially positioned crossovers and those with single pericentromeric crossovers become susceptible during female aging (Fig. 3D).

As with chromosome 18 (Bugge et al. 1998), segregation of chromosome 21 univalents is always associated with MI-type errors (Lamb et al. 1996; Oliver et al. 2008). Similarly, bivalents with a single distal chiasma are associated with MI-type trisomy 21 (Lamb et al. 1996; Oliver et al. 2008) and 16 (Nagaoka et al. 2012). In general, medial crossovers positioned toward the telomere appear to be prone to MItype errors, whereas those that are closer to the centromere are prone to MII-type errors. Notably, bivalents with single pericentromeric crossovers observed among trisomy 21 children born to older mothers are associated exclusively with MII-type errors (Oliver et al. 2008; Ghosh et al. 2009).

It could be argued that the shift in risk associated with the various chiasmate configurations described above simply reflects differences between oocytes ovulated early and late in reproductive life. For example, according to the "production line hypothesis," oocytes formed later in gestation have fewer crossovers and are the last to be ovulated (Edwards 1970). How- 
M. Herbert et al.

ever, a recent analysis of human fetal ovaries indicates that there is no such gradient in the number of crossovers formed during human development (Rowsey et al. 2014). Therefore, the more plausible explanation is that the shift in susceptibility of specific chiasmate configurations is a consequence of defects in chromosome structure acquired during an extended period of prophase arrest.

In relation to the persistence of univalent chromosomes as a risk factor for trisomy 21 in oocytes of older women, it is likely that compromised centromeric cohesion is a contributing factor. Assuming that, as in the mouse (Kouznetsova et al. 2007), univalent chromosomes evade the SAC by biorienting sisters, the combined effect of biorientation and loss of centromeric cohesion would greatly increase the risk of equational segregation of both sets of sisters during anaphase I. As a consequence, the MIIarrested oocytes would contain two free chromatids with a high risk of both being retained in the oocyte during anaphase II, resulting in an MI-type error (Fig. 3E). In contrast, the more robust protection of centromeric cohesion in oocytes of young women is likely to increase the probability of both univalents remaining intact, presumably resulting in their random segregation during anaphase I. Interestingly, oocytes of Sycp3 $3^{-1-}$ mice, which contain 1-4 univalent chromosomes, most commonly retain one intact univalent and one chromatid during MI in young females (Kouznetsova et al. 2007). This implies that one univalent stochastically loses centromeric cohesion and segregates equationally during MI (Fig. 3E). In this event, the chance of restoring euploidy during anaphase II would be increased compared with oocytes containing two free chromatids.

In relation to the risk of trisomy 21 arising from single chiasmate bivalents, the shift from subtelomeric to more centrally positioned crossovers during maternal aging is consistent with a progressive depletion of arm cohesin. In the case of a single subtelomeric chiasma, bivalent stability depends on the relatively short stretch of arm cohesion between the site of crossover formation and the telomere. This configuration, therefore, has a low threshold for cohesin loss and the chiasma becomes vulnerable to premature resolution even in young women. As predicted by the cohesin deterioration hypothesis, the more extensive depletion of cohesin during prolonged prophase arrest is likely to render more medially positioned chiasmata vulnerable to premature resolution in oocytes of older women. In both cases, the segregation pattern of prematurely disjoined homologs during anaphase I is predicted to be similar to that of univalent chromosomes, resulting in an increased risk of an MI type error (Fig. 3E). In support of the idea that chiasmata become prematurely resolved in human oocytes, studies on chromosome 16 indicate that the incidence of unpaired homologs in fully grown MI oocytes is more than double that observed in fetal oocytes (Garcia-Cruz et al. 2010b).

The emergence of bivalents with single pericentromeric crossovers as a risk factor in oocytes of older women, resulting exclusively in MII-type trisomy 21 (Oliver et al. 2008; Ghosh et al. 2009), suggests that, unlike other single chiasmate configurations, they undergo normal reductional segregation during MI. It is possible that the long stretch of distal arm cohesion makes pericentromeric chiasmata more resistant to the effects of arm cohesin depletion during prolonged prophase arrest. The persistence of a chiasma close to the centromere may, therefore, promote mono-orientation of sister centromeres and reductional segregation during anaphase I. This, coupled with loss of centromeric cohesion, would result in a pair of single sisters from the same homolog, which would culminate in an MII-type error if both are retained in the oocyte during anaphase II (Fig. $3 \mathrm{E})$. Whether the presence of a crossover close to the centromere might render centromeric cohesion particularly vulnerable to premature dissolution is currently unknown.

A surprisingly high proportion of trisomy 21 cases show multiple crossovers across all maternal ages (Fig. 3D). A recent study of trisomy cases inferred to have two crossovers indicates that the risk of MI-type trisomy is increased when they are positioned close together on the long arm of chromosome 21 (Oliver et al. 2012). Assuming that the stability of both chiasmata 
depends on the maintenance of arm cohesion between them, it could be postulated that the risk associated with shorter intercrossover distances is analogous to a single subtelomeric crossover as discussed above. In addition, it was reported that bivalents with two chiasmata are at risk of MII-type errors if one is positioned in the pericentromeric region (Oliver et al. 2012). Consistent with findings for single chiasmate pericentromeric bivalents, the proximity of the crossover to the centromere is positively correlated with the risk of missegregation in older women (Oliver et al. 2012). Together, these data imply that the proposed protective effect of an increased number of crossovers (Kong et al. 2004) does not apply to all chromosomes. In the case of small chromosomes, the data from trisomy 21 cases indicate that the risk of missegregation is increased if two crossovers are located in close proximity or in which one of a pair of crossovers is located too close to the centromere.

The pathways to missegregation proposed above (Fig. 3E) reconcile age-related premature loss of centromeric cohesion with evidence from population-based studies on trisomy 21 . However, it is worth noting that the correlation between the risk of trisomy 21 and specific chiasmate configurations in older women is complicated by the fact that oocytes from older women are frequently aneuploid for multiple chromosomes (Handyside et al. 2012; Fragouli et al. 2013; Franasiak et al. 2014), which is associated with early developmental arrest. Thus, reduced prevalence of some chiasmate configurations may reflect early embryonic loss, rather than a real age-related shift in the risk of missegregation. The ongoing development of robust technologies for DNA sequencing of oocytes and polar bodies has the potential to provide a more comprehensive picture of the relationships among chiasmate configurations, female age, and the risk of missegregation.

\section{CONCLUDING REMARKS}

Advances in our understanding of the mechanisms responsible for regulating chromosome structure and movement during meiosis have set the scene for formulating and testing hy-
Human Aneuploidy, Infertility, and Maternal Age

potheses relating to the molecular mechanisms underlying aneuploidy in oocytes ovulated late in life. A growing body of evidence indicating that mouse oocytes show an age-related increase in chromosome missegregation (Chiang et al. 2010; Lister et al. 2010; Sebestova et al. 2012) also represents a significant advance. These recent findings challenge the long-held view that mice show only a very minor age-related increase in oocyte aneuploidy (Brook et al. 1984). The disparity may be linked to the use of live-cell imaging to monitor chromosome movements during anaphase and/or the use of older females ( $>12 \mathrm{mo}$ ) in more recent studies. In any case, the findings imply that the mouse is a useful model for female reproductive aging, which, together with increasingly powerful genetic techniques, opens up a new era in which it is possible for hypothesis-driven research to unravel the molecular mechanisms and primary causes of chromosome missegregation during female reproductive aging. However, experiments involving aged mice require special attention to control for variables, such as diet, environment, reproductive history, and obesity.

In parallel with advances in our understanding of the molecular mechanisms underlying chromosome segregation errors during reproductive aging, a number of emerging clinical options may help improve reproductive outcome for older women. Without the use of donated oocytes, conventional IVF treatments can do little to increase the chance of pregnancy for older women. Although the outcome of IVF treatment may be improved by selecting euploid oocytes (Geraedts et al. 2011), whether any interventions can be designed to rescue fertility in women who produce no euploid oocytes remains controversial. Procedures, such as oocyte cytoplasmic donation or mitochondrial augmentation of MII-arrested oocytes (Chappel 2013), have been proposed as a means of boosting fertility in older women. However, given the growing body of evidence that defects in centromeric cohesion are a major cause of aneuploidy in human oocytes from older women, it is difficult to envisage how interventions, such as mitochondrial augmentation, could prevent these from segregating randomly during anaphase II. 
M. Herbert et al.

The possibility of developing effective interventions at an earlier stage of oogenesis was raised by a recent report that fertility of postmenopausal women could be restored by ex vivo pharmacological activation of Akt to induce activation of primordial follicles remaining in the ovary after menopause. Remarkably, regrafting of the treated ovarian tissue resulted in pregnancy, but only in young women who had undergone premature ovarian failure (Kawamura et al. 2013). The efficacy of this approach in restoring fertility in older women may depend on the extent to which the resting pool of oocytes is susceptible to depletion of chromosomal cohesin.

Whatever the promise of scientific and technological developments, the trend toward delaying motherhood is ultimately a lifestyle issue. Beyond the personal tragedy of involuntary childlessness, this problem has major implications for health economics. These include costs associated with prenatal testing, together with the medical costs of spontaneous and induced abortions. Moreover, older women who carry a pregnancy to term are at an increased risk of a variety of complications, including preterm delivery, fetal death, and stillbirths (Schmidt et al. 2012). There are also broader social and economic implications related to the demographic structure in developed economies. Despite these societal challenges, the issue of female reproductive aging receives little or no attention in the public health forum. Given the increasing dimensions of the problem, there is a pressing need for a more holistic approach to family planning, in which the current emphasis on preventing pregnancy is accompanied by information and education on the risks associated with delaying it. Real progress in combating this growing problem in reproductive health will also require that policymakers identify and address the socioeconomic barriers facing younger women who wish to start a family.

\section{ACKNOWLEDGMENTS}

We acknowledge Wolfgang Zachariae and Ian Adams for their help in the critical reading of this work. We apologize to authors whose work was not cited because of a lack of space. Research in the laboratory is supported by the United Kingdom Medical Research Council and Wellcome Trust.

\section{REFERENCES}

Adhikari D, Liu K. 2009. Molecular mechanisms underlying the activation of mammalian primordial follicles. Endocr Rev 30: 438-464.

Angell R. 1991. Predivision in human oocytes at meiosis I: A mechanism for trisomy formation in man. Hum Genet 86: $383-387$.

Angell R. 1997. First meiotic division non-disjunction in human oocytes. Am J Hum Genet 61: 23-32.

Azoury J, Lee KW, Georget V, Rassinier P, Leader B, Verlhac MH. 2008. Spindle positioning in mouse oocytes relies on a dynamic meshwork of actin filaments. Curr Biol 18: 1514-1519.

Baart EB, Martini E, Eijkemans MJ, Van Opstal D, Beckers NGM, Verhoeff A, Macklon NS, Fauser BCJM. 2007. Milder ovarian stimulation for in vitro fertilization reduces aneuploidy in the human preimplantation embryo: A randomized controlled trial. Hum Reprod 22: 980-988.

Battaglia DE, Goodwin P, Klein NA, Soules MR. 1996. Fertilization and early embryology: Influence of maternal age on meiotic spindle assembly oocytes from naturally cycling women. Hum Reprod 11: 2217-2222.

Baudat F, Imai Y, de Massy B. 2013. Meiotic recombination in mammals: Localization and regulation. Nat Rev Genet 14: 794-806.

Broekmans FJ, Knauff EAH, te Velde ER, Macklon NS, Fauser BC. 2007. Female reproductive ageing: Current knowledge and future trends. Trends Endocrinol Metab 18: $58-65$.

Brook JD, Gosden RG, Chandley AC. 1984. Maternal ageing and aneuploid embryos-Evidence that biological and not chronological age is the important influence. Hum Genet 66: 41-45.

Bugge M, Collins A, Petersen MB, Fisher J, Brandt C, Michael Hertz J, Tranebjaerg L, de Lozier-Blanchet C, Nicolaides P, Brondum-Nielsen K, et al. 1998. Non-disjunction of chromosome 18. Hum Mol Genet 7: 661-669.

Chappel S. 2013. The role of mitochondria from mature oocyte to viable blastocyst. Obstet Gynecol Int 2013: 183024.

Chiang T, Duncan FE, Schindler K, Schultz RM, Lampson MA. 2010. Evidence that weakened centromere cohesion is a leading cause of age-related aneuploidy in oocytes. Curr Biol 20: 1522-1528.

Coticchio G, Guglielmo MC, Dal Canto M, Fadini R, Mignini Renzini M, De Ponti E, Brambillasca F, Albertini DF. 2013. Mechanistic foundations of the metaphase II spindle of human oocytes matured in vivo and in vitro. Hum Reprod 28: 3271-3282.

Daniel K, Lange J, Hached K, Fu J, Anastassiadis K, Roig I, Cooke HJ, Stewart AF, Wassmann K, Jasin M, et al. 2011. Meiotic homologue alignment and its quality surveil- 
lance are controlled by mouse HORMAD1. Nat Cell Biol 13: 599-610.

Dokshin GA, Baltus AE, Eppig JJ, Page DC. 2013. Oocyte differentiation is genetically dissociable from meiosis in mice. Nat Genet 45: 877-883.

Duncan FE, Chiang T, Schultz RM, Lampson MA. 2009. Evidence that a defective spindle assembly checkpoint is not the primary cause of maternal age-associated aneuploidy in mouse eggs. Biol Reprod 81: 768-776.

Duncan FE, Hornick JE, Lampson MA, Schultz RM, Shea LD, Woodruff TK. 2012. Chromosome cohesion decreases in human eggs with advanced maternal age. Aging Cell 11: 1121-1124.

Dunson DB, Colombo B, Baird DD. 2002. Changes with age in the level and duration of fertility in the menstrual cycle. Hum Reprod 17: 1399-1403.

Eaton JW, Mayer AJ. 1953. The social biology of very high fertility among the Hutterites; the demography of a unique population. Hum Biol 25: 206-264.

Edson MA, Nagaraja AK, Matzuk MM. 2009. The mammalian ovary from genesis to revelation. Endocr Rev 30: 624712.

Edwards RG. 1970. Are oocytes formed and used sequentially in the mammalian ovary? Philos Trans R Soc Lond B Biol Sci 259: 103-105.

Ellison PT. 2010. Life historical perspectives on human reproductive aging. Ann NY Acad Sci 1204: 11-20.

Fragouli E, Alfarawati S, Goodall NN, Sanchez-Garcia JF, Colls P, Wells D. 2011. The cytogenetics of polar bodies: Insights into female meiosis and the diagnosis of aneuploidy. Mol Hum Reprod 17: 286-295.

Fragouli E, Alfarawati S, Spath K, Jaroudi S, Sarasa J, Enciso M, Wells D. 2013. The origin and impact of embryonic aneuploidy. Hum Genet 132: 1-13.

Franasiak JM, Forman EJ, Hong KH, Werner MD, Upham KM, Treff NR, Scott RT Jr. 2014. The nature of aneuploidy with increasing age of the female partner: A review of 15,169 consecutive trophectoderm biopsies evaluated with comprehensive chromosomal screening. Fertil Steril 101: $656-663$.

Gabriel AS, Thornhill AR, Ottolini CS, Gordon A, Brown APC, Taylor J, Bennett K, Handyside A, Griffin DK. 2011. Array comparative genomic hybridisation on first polar bodies suggests that non-disjunction is not the predominant mechanism leading to aneuploidy in humans. J Med Genet 48: 433-437.

Garcia-Cruz R, Brieno MA, Roig I, Grossmann M, Velilla E, Pujol A, Cabero L, Pessarrodona A, Barbero JL, Caldes MG. 2010a. Dynamics of cohesin proteins REC8, STAG3, SMC1 $\beta$ and SMC3 are consistent with a role in sister chromatid cohesion during meiosis in human oocytes. Hum Reprod 25: 2316-2327.

Garcia-Cruz R, Casanovas A, Brieno-Enriquez M, Robles P, Roig I, Pujol A, Cabero L, Durban M, Garcia Caldes M 2010b. Cytogenetic analyses of human oocytes provide new data on non-disjunction mechanisms and the origin of trisomy 16. Hum Reprod 25: 179-191.

Geraedts J, Montag M, Magli MC, Repping S, Handyside A, Staessen C, Harper J, Schmutzler A, Collins J, Goossens V, et al. 2011. Polar body array CGH for prediction of the
Human Aneuploidy, Infertility, and Maternal Age

status of the corresponding oocyte: Part I. Clinical results. Hum Reprod 26: 3173-3180.

Ghosh S, Feingold E, Dey SK. 2009. Etiology of Down syndrome: Evidence for consistent association among altered meiotic recombination, nondisjunction, and maternal age across populations. Am J Med Genet A 149A: $1415-1420$.

Gutierrez-Caballero C, Herran Y, Sanchez-Martin M, Suja JA, Barbero JL, Llano E, Pendas AM. 2011. Identification and molecular characterization of the mammalian $\alpha$ kleisin RAD21L. Cell Cycle 10: 1477-1487.

Gutierrez-Caballero C, Cebollero LR, Pendas AM. 2012. Shugoshins: From protectors of cohesion to versatile adaptors at the centromere. Trends Genet 28: 351-360.

Handyside AH. 2012. Molecular origin of female meiotic aneuploidies. Biochim Biophys Acta 1822: 1913-1920.

Handyside AH. 2013. 24-chromosome copy number analysis: A comparison of available technologies. Fertil Steril 100: $595-602$.

Handyside AH, Montag M, Magli MC, Repping S, Harper J, Schmutzler A, Vesela K, Gianaroli L, Geraedts J. 2012. Multiple meiotic errors caused by predivision of chromatids in women of advanced maternal age undergoing in vitro fertilisation. Eur J Hum Genet 20: 742-747.

Hassold TJ, Hunt P. 2001. To err (meiotically) is human: The genesis of human anuploidy. Nat Rev Genet 2: 280-291.

Hauf S, Watanabe N. 2004. Kinetochore orientation in mitosis and meiosis. Cell 119: 317-327.

Hauf S, Biswas A, Langegger M, Kawashima SA, Tsukahara T, Watanabe Y. 2007. Aurora controls sister kinetochore mono-orientation and homolog bi-orientation in meiosis I. EMBO J 26: $4475-4486$.

Herbert M, Levasseur M, Homer HA, Yallop K, Murdoch AP, McDougall A. 2003. Homologue disjunction in mouse oocytes requires proteolysis of securin and cyclin B1. Nat Cell Biol 5: 1023-1025.

Hirose Y, Suzuki R, Ohba T, Hinohara Y, Matsuhara H, Yoshida M, Itabashi Y, Murakami H, Yamamoto A. 2011. Chiasmata promote monopolar attachment of sister chromatids and their co-segregation toward the proper pole during meiosis I. PLoS Genet 7: e1001329.

Hochwagen A, Amon A. 2006. Checking your breaks: Surveillance mechanisms of meiotic recombination. Curr Biol 16: R217-R228.

Hodges CA, Revenkova E, Jessberger R, Hassold TJ, Hunt PA. 2005. SMC1 $\beta$-deficient female mice provide evidence that cohesins are a missing link in age-related nondisjunction. Nat Genet 37: 1351-1355.

Homer HA, McDougall A, Levasseur M, Murdoch AP, Herbert M. 2005. Mad2 is required for inhibiting securin and cyclin B degradation following spindle depolymerisation in meiosis I mouse oocytes. Reproduction 130: 829-843.

Ishiguro T, Tanaka K, Sakuno T, Watanabe Y. 2010. Shugoshin-PP2A counteracts casein-kinase-1-dependent cleavage of Rec8 by separase. Nat Cell Biol 12: 500-506.

Ishiguro K, Kim J, Fujiyama-Nakamura $\mathrm{S}$, Kato $\mathrm{S}$, Watanabe Y. 2011. A new meiosis-specific cohesin complex implicated in the cohesin code for homologous pairing. EMBO Rep 12: 267-275. 
M. Herbert et al.

Jaffe LA, Norris RP. 2010. Initiation of the meiotic prophaseto-metaphase transition in mammalian oocytes. In Oogenesis: The universal process (ed. Verlhac M-H, Villeneuve A), pp. 181-198. Wiley, New York.

Katis VL, Lipp JJ, Imre R, Bogdanova A, Okaz E, Habermann B, Mechtler K, Nasmyth K, Zachariae W. 2010. Rec8 phosphorylation by casein kinase 1 and Cdc7Dbf4 kinase regulates cohesin cleavage by separase during meiosis. Dev Cell 18: 397-409.

Kawamura K, Cheng Y, Suzuki N, Deguchi M, Sato Y, Takae S, Ho Ch, Kawamura N, Tamura M, Hashimoto S, et al. 2013. Hippo signaling disruption and Akt stimulation of ovarian follicles for infertility treatment. Proc Natl Acad Sci 110: 17474-17479.

Keeney S, Neale MJ. 2006. Initiation of meiotic recombination by formation of DNA double-strand breaks: Mechanism and regulation. Biochem Soc Trans 34: 523-525.

Kim KP, Weiner BM, Zhang L, Jordan A, Dekker J, Kleckner N. 2010. Sister cohesion and structural axis components mediate homolog bias of meiotic recombination. Cell 143: 924-937.

Kim J, Ishiguro K, Nambu A, Akiyoshi B, Yokobayashi S, Kagami A, Ishiguro T, Pendas AM, Takeda N, Sakakibara Y, et al. 2014. Meikin is a conserved regulator of meiosisI-specific kinetochore function. Nature 517: 466-471.

Kirkwood TBL, Shanley DP. 2010. The connections between general and reproductive senescence and the evolutionary basis of menopause. Ann NY Acad Sci 1204: 21-29.

Kitajima TS, Ohsugi M, Ellenberg J. 2011. Complete kinetochore tracking reveals error-prone homologous chromosome biorientation in mammalian oocytes. Cell 146: $568-581$.

Kong A, Barnard J, Gudbjartsson DF, Thorleifsson G, Jonsdottir G, Sigurdardottir S, Richardsson B, Jonsdottir J, Thorgeirsson T, Frigge ML, et al. 2004. Recombination rate and reproductive success in humans. Nat Genet 36: 1203-1206.

Kouznetsova A, Lister L, Nordenskjold M, Herbert M, Höög C. 2007. Bi-orientation of achiasmatic chromosomes in meiosis I oocytes contributes to aneuploidy in mice. Nat Genet 39: 966-968.

Kudo NR, Wassmann K, Anger M, Schuh M, Wirth KG, Xu H, Helmhart W, Kudo H, McKay M, Maro B, et al. 2006. Resolution of chiasmata in oocytes requires separase-mediated proteolysis. Cell 126: 135-146.

Kugou K, Fukuda T, Yamada S, Ito M, Sasanuma H, Mori S, Katou Y, Itoh T, Matsumoto K, Shibata T, et al. 2009. Rec8 guides canonical Spo11 distribution along yeast meiotic chromosomes. Mol Biol Cell 20: 3064-3076.

Kuliev A, Zlatopolsky Z, Kirillova I, Spivakova J, Cieslak Janzen J. 2011. Meiosis errors in over 20,000 oocytes studied in the practice of preimplantation aneuploidy testing. Reprod Biomed Online 22: 2-8.

Lamb NE, Freeman SB, Savage-Austin A, Pettay D, Taft L, Hersey J, Gu Y, Shen J, Saker D, May KM, et al. 1996. Susceptible chiasmate configurations of chromosome 21 predispose to non-disjunction in both maternal meiosis I and meiosis II. Nat Genet 14: 400-405.

Lamb NE, Feingold E, Savage A, Avramopoulos D, Freeman S, Gu Y, Hallberg A, Hersey J, Karadima G, Pettay D, et al. 1997. Characterization of susceptible chaisma configura- tion that increases the risk for maternal non-disjunction of chromosome 21. Hum Mol Genet 6: 1391-1399.

Lamb NE, Yu K, Shaffer J, Feingold E, Sherman SL. 2005. Association between maternal age and meiotic recombination for trisomy 21. Am J Hum Genet 76: 91-99.

Lambalk CB, van Disseldorp J, de Koning CH, Broekmans FJ. 2009. Testing ovarian reserve to predict age at menopause. Maturitas 63: 280-291.

Lara-Gonzalez P, Westhorpe F, Taylor S. 2012. The spindle assembly checkpoint. Curr Biol 22: R966-R980.

Lee J, Hirano T. 2011. RAD21L, a novel cohesin subunit implicated in linking homologous chromosomes in mammalian meiosis. J Cell Biol 192: 263-276.

Lee J, Kitajima TS, Tanno Y, Yoshida K, Morita T, Miyano T, Miyake M, Watanabe Y. 2008. Unified mode of centromeric protection by shugoshin in mammalian oocytes and somatic cells. Nat Cell Biol 10: 42-52.

Le Maire-Adkins R, Radke K, Hunt PA. 1997. Lack of checkpoint control at the metaphase/anaphase transition: A mechanism of meiotic nondisjunction in mammalian females. J Cell Biol 139: 1611-1619.

Lister LM, Kouznetsova A, Hyslop LA, Kalleas D, Pace SL, Barel JC, Nathan A, Floros V, Adelfalk C, Watanabe Y, et al. 2010. Age-related meiotic segregation errors in mammalian oocytes are preceded by depletion of cohesin and Sgo2. Curr Biol 20: 1511-1521.

Liu L, Keefe DL. 2008. Defective cohesin is associated with age-dependent misaligned chromosomes in oocytes. Reprod Biomed Online 16: 103-112.

Llano E, Gomez R, Gutierrez-Caballero C, Herran Y, Sanchez-Martin M, Vazquez-Quinones L, Hernandez T, de Alava E, Cuadrado A, Barbero JL, et al. 2008. Shugoshin2 is essential for the completion of meiosis but not for mitotic cell division in mice. Genes Dev 22: 2400-2413.

Loane M, Morris JK, Addor MC, Arriola L, Budd J, Doray B, Garne E, Gatt M, Haeusler M, Khoshnood B, et al. 2013. Twenty-year trends in the prevalence of Down syndrome and other trisomies in Europe: Impact of maternal age and prenatal screening. Eur J Hum Genet 21: 27-33.

McGee EA, Hsueh A. 2000. Initial and cyclic recruitment of ovarian follicles. Endocr Rev 21: 200-214.

McGuinness BE, Anger M, Kouznetsova A, Gil-Bernabé AM, Helmhart W, Kudo NR, Wuensche A, Taylor S, Hoog C, Novak B, et al. 2009. Regulation of APC/C activity in oocytes by a Bub1-dependent spindle assembly checkpoint. Curr Biol 19: 369-380.

McNicoll F, Stevense M, Jessberger R. 2013. Cohesin in gametogenesis. In Current topics in developmental biology, pp. 1-34. Academic, New York.

Mehlmann LM. 2005. Stops and starts in mammalian oocytes: Recent advances in understanding the regulation of meiotic arrest and oocyte maturation. Reproduction 130: 791-799.

Monje-Casas F, Prabhu VR, Lee BH, Boselli M, Amon A. 2007. Kinetochore orientation during meiosis is controlled by aurora B and the monopolin complex. Cell 128: $477-490$.

Moore DP, Orr-Weaver TL. 1998. Chromosome segregation during meiosis: Building an unambivalent bivalent. Curr Top Dev Biol 37: 263-299. 
Morris JK, Alberman E. 2009. Trends in Down's syndrome live births and antenatal diagnoses in England and Wales from 1989 to 2008: Analysis of data from the National Down Syndrome Cytogenetic Register. BMJ 339: b3794.

Musacchio A, Salmon ED. 2007. The spindle-assembly checkpoint in space and time. Nat Rev Mol Cell Biol 8: 379-393.

Nagaoka SI, Hodges CA, Albertini DF, Hunt PA. 2011. Oocyte-specific differences in cell-cycle control create an innate susceptibility to meiotic errors. Curr Biol 21: 651-657.

Nagaoka SI, Hassold TJ, Hunt PA. 2012. Human aneuploidy: Mechanisms and new insights into an age-old problem. Nat Rev Genet 13: 493-504.

Nasmyth K. 2011. Cohesin: A catenase with separate entry and exit gates? Nat Cell Biol 13: 1170-1177.

Nasmyth K, Haering CH. 2009. Cohesin: Its roles and mechanisms. Annu Rev Genet 43: 525-558.

Neale MJ, Keeney S. 2006. Clarifying the mechanics of DNA strand exchange in meiotic recombination. Nature $\mathbf{4 4 2}$ $153-158$.

Niault T, Hached K, Sotillo R, Sorger PK, Maro B, Benezra R, Wassmann K. 2007. Changing Mad2 levels affects chromosome segregation and spindle assembly checkpoint control in female mouse meiosis I. PLOS ONE 2: e1165.

Nonaka K, Miura T, Peter K. 1994. Recent fertility decline in Dariusleut Hutterites: An extension of Eaton and Mayer's Hutterite fertility study. Hum Biol 66: 411-420.

Oliver TR, Feingold E, Yu K, Cheung V, Tinker S, YadavShah M, Masse N, Sherman SL. 2008. New insights into human nondisjunction of chromosome 21 in oocytes. PLoS Genet 4: e1000033.

Oliver TR, Tinker SW, Allen EG, Hollis N, Locke AE, Bean LH, Chowdhury R, Begum F, Marazita M, Cheung V, et al. 2012. Altered patterns of multiple recombinant events are associated with nondisjunction of chromosome 21. Hum Genet 131: 1039-1046.

Page SL, Hawley RS. 2004. The genetics and molecular biology of the synaptonemal complex. Annu Rev Cell Dev Biol 20: 525-558.

Pellestor F, Andréo B, Arnal F, Humeau C, Demaille J. 2003. Maternal aging and chromosomal abnormalities: New data drawn from in vitro unfertilized human oocytes. Hum Genet 112: 195-203.

Pellestor F, Andreo B, Anahory T, Hamamah S. 2006. The occurrence of aneuploidy in human: Lessons from the cytogenetic studies of human oocytes. Eur J Med Genet 49: $103-116$.

Penrose LS. 1933. The relative effects of paternal and maternal age in mongolism. J Genet 88: 9-14.

Peters JM, Nishiyama T. 2012. Sister chromatid cohesion. Cold Spring Harb Perspect Biol 4: a011130.

Petronczki M, Siomos MF, Nasmyth K. 2003. Un menage a quatre: The molecular biology of chromosome segregation in meiosis. Cell 112: 423-440.

Qiao H, Prasada Rao HBD, Yang Y, Fong JH, Cloutier JM, Deacon DC, Nagel KE, Swartz RK, Strong E, Holloway JK, et al. 2014. Antagonistic roles of ubiquitin ligase HEI10 and SUMO ligase RNF212 regulate meiotic recombination. Nat Genet 46: 194-199.
Human Aneuploidy, Infertility, and Maternal Age

Rattani A, Wolna M, Ploquin M, Helmhart W, Morrone S, Mayer B, Godwin J, Xu W, Stemmann O, Pendas A, et al. 2013. Sgol2 provides a regulatory platform that coordinates essential cell cycle processes during meiosis I in oocytes. eLife 2: $\mathrm{e} 01133$.

Revenkova E, Herrmann K, Adelfalk C, Jessberger R. 2010. Oocyte cohesin expression restricted to predictyate stages provides full fertility and prevents aneuploidy. Curr Biol 20: $1529-1533$.

Reynolds A, Qiao H, Yang Y, Chen JK, Jackson N, Biswas K, Holloway JK, Baudat F, de Massy B, Wang J, et al. 2013. RNF212 is a dosage-sensitive regulator of crossing-over during mammalian meiosis. Nat Genet 45: 269-278.

Risch N, Stein Z, Kline J, Warburton D. 1986. The relationship between maternal age and chromosome size in autosomal trisomy. Am J Hum Genet 39: 68-78.

Roberts R, Iatropoulou A, Ciantar D, Stark J, Becker DL, Franks S, Hardy K. 2005. Follicle-stimulating hormone affects metaphase I chromosome alignment and increases aneuploidy in mouse oocytes matured in vitro. Biol Reprod 72: 107-118.

Robinson WP, Kuchinka BD, Bernasconi F, Petersen MB, Schulze A, Brondum-Nielsen K, Christian SL, Ledbetter DH, Schinzel AA, Horsthemke B, et al. 1998. Maternal meiosis I non-disjunction of chromosome 15: Dependence of the maternal age effect on level of recombination. Hum Mol Genet 7: 1011-1019.

Rowsey R, Gruhn J, Broman KW, Hunt PA, Hassold T. 2014. Examining variation in recombination levels in the human female: A test of the production-line hypothesis. Am J Hum Genet 95: 108-112.

Sakuno T, Tanaka K, Hauf S, Watanabe Y. 2011. Repositioning of Aurora B promoted by chiasmata ensures sister chromatid mono-orientation in meiosis I. Dev Cell 21: 534-545.

Sandalinas M, Marquez C, Munne S. 2002. Spectral karyotyping of fresh, non-inseminated oocytes. Mol Hum Reprod 8: $580-585$.

Sauer MV. 1998. The impact of age on reproductive potential: Lessons learned from oocyte donation. Maturitas 30: 221-225.

Schmidt A, Rauh NR, Nigg EA, Mayer TU. 2006. Cytostatic factor: An activity that puts the cell cycle on hold. J Cell Sci 119: 1213-1218.

Schmidt L, Sobotka T, Bentzen JG, Nyboe Andersen A. 2012. Demographic and medical consequences of the postponement of parenthood. Hum Reprod Update 18: 29-43.

Schuh M, Ellenberg J. 2008. A new model for asymmetric spindle positioning in mouse oocytes. Curr Biol 18: 1986-1992.

Sebestova J, Danylevska A, Novakova L, Kubelka M, Anger M. 2012. Lack of response to unaligned chromosomes in mammalian female gametes. Cell Cycle 11: 3011-3018.

Sharma R, Biedenharn KR, Fedor JM, Agarwal A. 2013. Lifestyle factors and reproductive health: Taking control of your fertility. Reprod Biol Endocrinol 11: 66.

Shomper M, Lappa C, FitzHarris G. 2014. Kinetochore microtubule establishment is defective in oocytes from aged mice. Cell Cycle 13: 1171-1179. 


\section{Herbert et al.}

Svetlanov A, Cohen PE. 2004. Mismatch repair proteins, meiosis, and mice: Understanding the complexities of mammalian meiosis. Exp Cell Res 296: 71-79.

Swann K, Lai FA. 2012. PLCל and the initiation of $\mathrm{Ca}^{2+}$ oscillations in fertilizing mammalian eggs. Cell Calcium 53: 55-62.

Tachibana-Konwalski K, Godwin J, van der Weyden L, Champion L, Kudo NR, Adams DJ, Nasmyth K. 2010. Rec8-containing cohesin maintains bivalents without turnover during the growing phase of mouse oocytes. Genes Dev 24: 2505-2516.

Tachibana-Konwalski K, Godwin J, Borsos M, Rattani A, Adams DJ, Nasmyth K. 2013. Spindle assembly checkpoint of oocytes depends on a kinetochore structure determined by cohesin in meiosis I. Curr Biol 23: $2534-$ 2539.

Templeton A, Morris JK, Parslow W. 1996. Factors that affect outcome of in-vitro fertilisation treatment. Lancet 348: 1402-1406.

te Velde ER, Dorland M, Broekmans FJ. 1998. Age at menopause as a marker of reproductive ageing. Maturitas 30: 119-125.

Toth A, Rabitsch KP, Galova M, Schleiffer A, Buonomo SBC Nasmyth K. 2000. Functional genomics identifies monopolin: A kinetochore protein required for segregation of homologs during meiosis I. Cell 103: 1155-1168.

Touati SA, Cladiere D, Lister LM, Leontiou I, Chambon JP, Rattani A, Bottger F, Stemmann O, Nasmyth K, Herbert $\mathrm{M}$, et al. 2012. Cyclin A2 is required for sister chromatid segregation, but not separase control, in mouse oocyte meiosis. Cell Rep 2: 1077-1087.

Tsutsumi M, Fujiwara R, Nishizawa H, Ito M, Kogo H, Inagaki H, Ohye T, Kato T, Fujii T, Kurahashi H. 2014. Agerelated decrease of meiotic cohesins in human oocytes. PLOS ONE 9: e96710.

Volarcik K, Sheean L, Goldfarb J, Woods L, Abdul-Karim FW, Hunt P. 1998. The meiotic competence of in-vitro matured human oocytes is influenced by donor age: $\mathrm{Ev}$ idence that folliculogenesis is compromised in the reproductively aged ovary. Hum Reprod 13: 154-160.

Von Stetina JR, Orr-Weaver TL. 2011. Developmental control of oocyte maturation and egg activation in metazoan models. Cold Spring Harb Perspect Biol 3: a005553.

Wassmann K, Niault T, Maro B. 2003. Metaphase I arrest upon activation of the Mad2-dependent checkpoint in mouse oocytes. Curr Biol 13: 1596-1608.

Watanabe Y. 2012. Geometry and force behind kinetochore orientation: Lessons from meiosis. Nat Rev Mol Cell Biol 13: $370-382$.

Woods LM, Hodges CA, Baart E, Baker SM, Liskay M, Hunt PA. 1999. Chromosome influence on meiotic spindle assembly: Abnormal meiosis I in female Mlh1 mutant mice. J Cell Biol 145: 1395-1406.

Yun Y, Lane SIR, Jones KT. 2014. Premature dyad separation in meiosis II is the major segregation error with maternal age in mouse oocytes. Development 141: 199 208. 


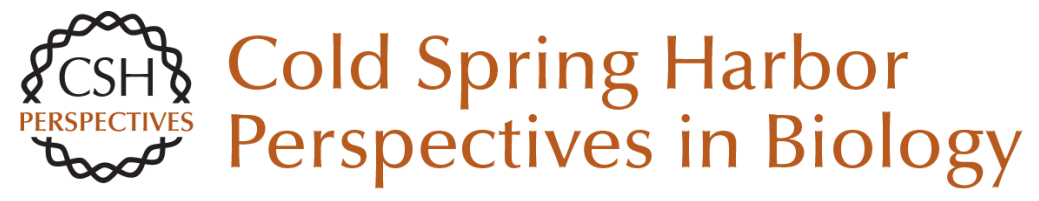

\title{
Meiosis and Maternal Aging: Insights from Aneuploid Oocytes and Trisomy Births
}

\author{
Mary Herbert, Dimitrios Kalleas, Daniel Cooney, Mahdi Lamb and Lisa Lister
}

Cold Spring Harb Perspect Biol 2015; doi: 10.1101/cshperspect.a017970

\section{Subject Collection DNA Recombination}

Meiotic Recombination: The Essence of Heredity Neil Hunter

Regulation of Recombination and Genomic Maintenance Wolf-Dietrich Heyer

Initiation of Meiotic Homologous Recombination: Flexibility, Impact of Histone Modifications, and Chromatin Remodeling Lóránt Székvölgyi, Kunihiro Ohta and Alain Nicolas

Mechanism and Regulation of Meiotic

Recombination Initiation Isabel Lam and Scott Keeney

Homologous Recombination and Human Health: The Roles of BRCA1, BRCA2, and Associated Proteins Rohit Prakash, Yu Zhang, Weiran Feng, et al.

\section{Cell Biology of Mitotic Recombination} Michael Lisby and Rodney Rothstein

DNA-Pairing and Annealing Processes in Homologous Recombination and Homology-Directed Repair Scott W. Morrical
An Overview of the Molecular Mechanisms of Recombinational DNA Repair Stephen C. Kowalczykowski

Recombination, Pairing, and Synapsis of Homologs during Meiosis Denise Zickler and Nancy Kleckner

DNA Strand Exchange and RecA Homologs in Meiosis M. Scott Brown and Douglas K. Bishop

Meiosis and Maternal Aging: Insights from Aneuploid Oocytes and Trisomy Births Mary Herbert, Dimitrios Kalleas, Daniel Cooney, et al.

Mismatch Repair during Homologous and Homeologous Recombination Maria Spies and Richard Fishel

Mechanisms of Gene Duplication and Amplification Andrew B. Reams and John R. Roth

The Role of Double-Strand Break Repair Pathways at Functional and Dysfunctional Telomeres Ylli Doksani and Titia de Lange

For additional articles in this collection, see http://cshperspectives.cshlp.org/cgi/collection/

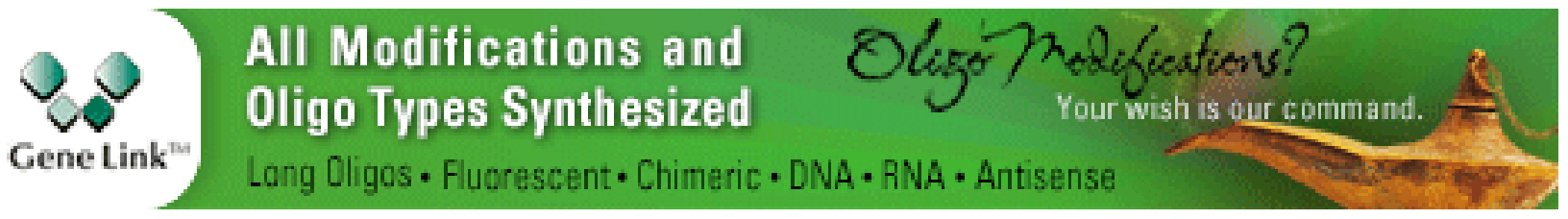




\section{Mediators of Homologous DNA Pairing}

Alex Zelensky, Roland Kanaar and Claire Wyman
Regulation of DNA Pairing in Homologous

Recombination

James M. Daley, William A. Gaines, YoungHo Kwon, et al.

For additional articles in this collection, see http://cshperspectives.cshlp.org/cgi/collection/

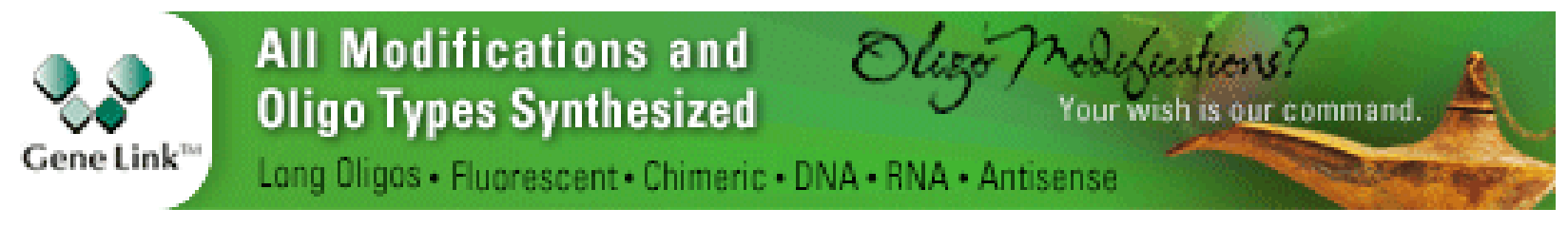

Copyright @ 2015 Cold Spring Harbor Laboratory Press; all rights reserved 